\title{
BIO-NANOPARTICLES: GREEN SYNTHESIS OF GOLD NANOPARTICLES AND ASSESSMENT OF BIOLOGICAL EVALUATION
}

\author{
RATIH DYAH PERTIWI ${ }^{1,4}$, SUWALDI $^{2}$, ERNA PRAWITA SETYOWATI ${ }^{3}$, RONNY MARTIEN $^{2 *}$
}

${ }^{1}$ Department of Pharmacy, Faculty of Health Sciences, Universitas Esa Unggul, Jl Arjuna no 9A Jakarta, 11510, 2Department of Pharmaceutics, Faculty of Pharmacy, Universitas Gadjah Mada, Sekip Utara Yogyakarta, 55281, ${ }^{3}$ Department of Pharmaceutical Biology, Faculty of Pharmacy, Universitas Gadjah Mada, Sekip Utara, Yogyakarta, 55281, ${ }^{4}$ Doctoral Program in Pharmaceutical Science, Faculty of Pharmacy, Universitas Gadjah Mada, Sekip Utara, Yogyakarta, Indonesia 55281

Email: ronnymartien@ugm.ac.id

Received: 08 Jul 2019, Revised and Accepted: 23 Sep 2019

ABSTRACT

Objective: The design like bio-nano particles are beneficial over chemical and physical composition due to the eco-friendly and lower-cost synthesis of nanoparticles. The current study was purposed for the biosynthesis of gold nanoparticles (GNPs) and their antioxidant evaluation.

Methods: Aqua extract of Muntingia calabura, Linn was applied for the synthesis of GNPs and confirmed by UV visible and ATR-Fourier Transform Infra-Red (ATR-FTIR) spectroscopy. Transmission Electron Microscope and Particle Size Analyser were used for the shape zeta potential and determination of size. Antioxidant activity was examined by DPPH (1,1 diphenyl-2-picryl-hydrazyl) radical scavenging method.

Results: The result showed that UV-vis absorption spectra of $\mathrm{H} \mathrm{Au} \mathrm{Cl}_{4}$ at $290 \mathrm{~nm}$ while absorption spectra of biosynthesis gold nanoparticles at 540 $\mathrm{nm}$. The forming of nanoparticles were spherical, having an average particle size of $88 \mathrm{~nm}$, and the result of zeta potential was $9.5 \mathrm{mV}$. Analysis of ATR-FTIR revealed the possible involvement of phytochemical constituents in gold nanoparticles of aqua extract. Green synthesized nanoparticles showed enhanced antioxidant properties.

Conclusion: Green synthesized GNPs showed enhanced biological activities. Present results also support the benefit of using the biosynthesis method for the production of gold nanoparticles that have the potential of antioxidant and biology activities.

Keywords: Green synthesis, Gold Nanoparticles, Antioxidant, Muntingia calabura, Biological activities

(C) 2019 The Authors. Published by Innovare Academic Sciences Pvt Ltd. This is an open-access article under the CC BY license (http://creativecommons.org/licenses/by/4.0/) DOI: http://dx.doi.org/10.22159/ijap.2019v11i6.34826

\section{INTRODUCTION}

The development of science and technology has led several studies in nanotechnology which potential breakthroughs in good fields such as materials and manufacturing, health care, and medicine. Among the nanoparticles, the bio-reduced gold and silver nanoparticles have gained the utmost importance in biomedical applications. The size and surface morphology play an essential role in controlling the chemical, physical, and electronic properties of nanomaterials [1]. Both $\mathrm{Au}$ and $\mathrm{Ag}$ nanoparticles are the main leading robust nanomaterial provides an excellent platform in biology biomedical research and applications [2]. The characteristic of gold nanoparticles is different from the mass, as a gold nanoparticle is a wine red solution while the mass gold is a yellow solid. The gold nanoparticles can be manufactured into a shapes variety. The shape and size of gold nanoparticles very influence their characters and properties. Due to their broad spread applications in diagnosis, targeted drug delivery system, and therapeutics due to their minimal small size, physical and chemical properties, high surface area, stability, non-cytotoxicity optics, gold nanoparticles have revolutionized the field of targeted medicine $[3,4]$. Preparation of gold nanoparticles is not only comfortable but is also highly flexible since they can be synthesized in different sizes and shapes [2]. French scientist research in which they formulated to synthesize fluorescent gold nanoparticles inside human hair. They showed that the gold colour remained even after repeated washings [5].

Much of the study is devoted to the study of the synthesis, stabilization, and functionalization of the GNPs. The most common reduction agents reported are sodium citrate, transferrin, and Natrium Borohydride while general species used for functionalization include various oligonucleotides, peptides, antibodies, and lipids. The interest in GNPs is primarily due to the relative ease of their synthesis, with reasonable control of their shapes, size, their optical characteristics, and their high biocompatibility [6].
After the progress of the concept of green nanoparticle prepared, there has been a growing need for environmentally benign metal nanoparticle synthesis process that does not use toxic chemicals in the synthesis protocols to avoid adverse effects in medical applications [7]. In the last decade, biosynthesis of metal nanoparticles is a growing need to reveal clean, nontoxic chemicals, environmentally mild solvents, and renewable materials and hence the focus turned towards green chemistry and bioprocesses [8]. The influence for green chemistry and bioprocesses approaches from nature through fungi, bacteria, yeast, and plant extracts in the synthesis of biocompatible gold and semiconductor nanoparticles [9]. The use of non-toxic chemicals, environmentally friendly solvents and renewable materials are some critical issues that deserve important consideration in green synthetic strategies [7].

To reduce further chemical interventions and to improve the sustainability of the process, alternative biosynthetic green methods that utilize plant-based phytochemicals for reduction of metal ions provide an inherently green approach to nanotechnology, also referred to as green nanotechnology. Recently, several studies have demonstrated the dual role of whole plant extracts and pure compounds isolated from plants as active, reducing agents and as stabilizers, to provide a robust coating on the biocompatible GNPs. The reactive phytochemical species include polyphenols such as flavonoids and non-flavonoids, the abundant antioxidants in human food [10].

Muntingia calabura $\mathrm{L}$ is a fast-growing thin tree, native to the American continent and is commonly was conserved in warm areas of the Asian region [11]. The extract of $M$. calabura plant displayed excellent antioxidant activity and the antioxidant activity of $M$. calabura plant is may due to the presence of ascorbic acid, flavonoids, and polyphenols [12]. The current study designed for green synthesis of gold nanoparticles (GNPs) with extracts of $M$. calabura, $\mathrm{L}$ and their biological evaluation. 


\section{MATERIALS AND METHODS}

\section{Materials}

The Muntingia calabura was collected from the Spice and Medicinal Plant Research Institute, Bogor, Indonesia. Au Foil (PT Antam, Indonesia), Gummy Arabic, 1,1-Diphenyl-2-Picril-Hydrazil (DPPH), Methanol, Bovine Serum Albumin (Sigma-Aldrich), Phosphate Buffer Saline (IPHA), PD-10 column (GE Health Care, England), Aqua Bidestilata (IPHA, Indonesia),Aqua Regia, Sodium Dibasic Phosphate (Merck).

\section{Preparation of the plant extract}

The collected leaves of $M$. calabura were washed thoroughly with distilled water. Dried M. calabura leaves were sliced into small pieces and $5.00 \mathrm{~g}$ of sample was added to $100 \mathrm{ml}$ of double-distilled water and heated at $70{ }^{\circ} \mathrm{C}$ for $15 \mathrm{~min}$. The mixture was stored to room temperature and filtered through Whatman No. 1 filter paper. The aqueous extract was cooled in a refrigerator for further studies [13].

\section{Preparation of the $\mathrm{HAuCl}_{4}$, and gummy arabic solutions}

A Solution of $0.002 \mathrm{M} \mathrm{HAuCl}_{4}$ was prepared by dissolving 20.1612 $\mathrm{mg}$ of $\mathrm{Au}$ foil in hot aqua regia that mixture from $\mathrm{HCl}$ (aq) and $\mathrm{HNO}_{3(\mathrm{aq})}$ (3:1). This solution was heated, and $10 \mathrm{ml}$ of an aqua pro injection was added. The heating and add aqua pro injection were operated three times. The final solution was added to a $0.01 \mathrm{M} \mathrm{HCl}$ solution to achieve the $0.002 \mathrm{M} \mathrm{HAuCl}_{4}$ solution [14].

The Gummy Arabic solution $8.2 \mathrm{ml}$ and $0.3 \mathrm{ml}$ aliquot of the aqua pro injection were heated to $55^{\circ} \mathrm{C}$ and continuously stirred. To this hot Gummy Arabic solution, $1.5 \mathrm{ml}$ of the $0.002 \mathrm{M} \mathrm{HAuCl}_{4}$ solution was added with continuous stirring [14].

\section{Biosynthesis of gold nanoparticles}

Synthesis of GNPs was carried out at room temperature by adding $1.0 \mathrm{ml}$ Muntigia calabura leaves aqueous extract to $9.0 \mathrm{ml}$ of $0,002 \mathrm{M}$ $\mathrm{HAuCl}_{4}[15]$. The result was incubated at room temperature in dark condition for $24 \mathrm{hr}$ and observed for any change in colour. During the solution containing Muntingia, the color changed orange then yellow and purple-red after about $10 \mathrm{~min}$. The reaction mixture was mixed for an additional $30 \mathrm{~min}$ [10].

\section{Characterization}

Synthesis of GNPs was done at room temperature by adding of aqueous leaves extract of Muntigia calabura and added to $9.0 \mathrm{ml}$ of $0,002 \mathrm{M} \mathrm{HAuCl}_{4}$ [15]. The reaction was nursed at room temperature in dark condition for $24 \mathrm{~h}$ and GNPs formation was detected by changed colour from orange then yellow to purple-red after about $10 \mathrm{~min}$. To find out the particles size distribution, the synthesized GNPs was dispersed and carried out with an SZ100 model HORIBA nanoparticle analyser (HORIBA Ltd., Kyoto, Japan). Zeta potential describes the electrical potential in the double layer of ions surrounding a particle at the boundary of the particle surface and the adsorbed ions in the diffuse layer. Zeta potentials were determined with an SZ100 model HORIBA nanoparticle analyser (HORIBA Ltd., Kyoto, Japan). The Zeta Potential describes the electrical potential in the double layer of ions surrounding a particle at the boundary of the particle surface and the adsorbed ions in the diffuse layer. Zeta potentials were determined with a SZ100 model HORIBA nanoparticle analyser (HORIBA Ltd., Kyoto, Japan).

\section{Spectroscopic measurements}

The biological reduction of $\mathrm{H} \mathrm{AuCl}_{4}$ was determined using UV-Visible spectrophotometer (TECAN, Switzerland). The formation of ruby red colour confirms the synthesis of GNPs. The confirmation of colour change was characterised by the absorption peak over the range of a from $300 \mathrm{~nm}$ to $700 \mathrm{~nm}$.

\section{The radical scavenging activity}

The radical scavenging activity of the synthesized GNPs was determined using 1, 1-diphenyl-2-picrylhydrazyl (DPPH) assay. Different concentrations of $1 \mathrm{ml}$ the synthesized GNPs was mixed with $5 \mathrm{ml}$ of $0,1 \mathrm{mmol}$ methanolic DPPH and incubated in the dark at room temperature for $20 \mathrm{~min}$. After incubation, the absorbance of the samples was measured by using UV-vis Spectrophotometer at $517 \mathrm{~nm}$ and methanolic DPPH reagent without sample was used as a control [16]. The ability to scavenge DPPH radical was calculated by the following equation:

$$
\text { Inhibition (\%) }=\frac{\text { Absorbance Control-Absorbance test }}{\text { Absorbance Control }} \times 100 \text { [16] }
$$

\section{Statistical analysis}

Each experiment was carried out in triple replicates and the results were expressed as the mean \pm standard deviation $(n=3)$. The mean and standard deviation were measured using Microsoft Excel.

\section{RESULTS AND DISCUSSION}

\section{Biosynthesis of gold nanoparticles}

The matured collected leaves are washed with distilled water, sliced into small pieces and boiled in distilled water to obtained extract. The extract can be purified by filtration with Whatman No. 1 filter paper [17]. Gold Nanoparticles (GNPs) were prepared with The aqueous extract of the M. calabura, and the synthesized GNPs were indicated from the colour change from yellow to ruby red after 1 hour after stirring. The formation of the ruby red colour showed that the completion of a synthesis process the biosynthesis of GNPs. The plant extract contains different biomolecules like enzymes, amino acids, proteins, sugars, and other traces of metals [18]. These metabolites are strongly comprised of the bio-reduction process. The usual reaction was $\mathrm{Au}^{+}$ions reduction into metallic $\mathrm{Au}{ }^{\circ}$ nanoparticles in the presence of metabolites and redox enzymes. The reaction is given below.

$\mathrm{HAu}_{+} \mathrm{Cl}_{4}+4 \mathrm{H}_{2} 0+$ extracts of plant $\rightarrow \mathrm{Au}_{0}$ NPs+by-products [18]

Colour changes during GNP synthesis are caused by excitation of surface plasmon resonance, which is expressed as characteristic features of synthesized nanoparticles in the study of diagnostic and therapeutic applications of gold nanoparticles depending on their synthesis and characterization. The absorption peak was recorded at $540 \mathrm{~nm}$ in the spectrum of UV-visible. The peak of the nanoparticles is broadened in the absorption spectrum. For the biological and biomedical application, it is found that the broadening of the peak in the absorption spectra indicates the poly-dispersion of the nanoparticles from a study involving the peak of absorption and properties of scattering of gold nanoparticles [2]. UVvis absorption spectra maximum of $\mathrm{H} \mathrm{Au} \mathrm{Cl}_{4}$ at $290 \mathrm{~nm}$, while absorption spectra maximum of gold nanoparticles with extract of Muntingia at 540 $\mathrm{nm}$ (fig. 1). It displayed that these changes are consistent with an initial rapid reduction of $\mathrm{Au}^{(\mathrm{III})}$ to $\mathrm{Au}\left({ }^{\circ}\right)$ and showed that the biosynthesis gold nanoparticles had been formed. Furthermore, the presence of an absorption band at $550 \mathrm{~nm}$ is suggestive of the presence of gold nanoparticles.

\section{Characterization of biosynthesized gold nanoparticles}

The characterization of gold nanoparticles is an essential step in the biosynthesis of gold nanoparticles. The stability, shape, size, surface area and their dispersion of nanoparticles are the critical properties used to characterise the synthesis of gold nanoparticles. The characterization of nanoparticles obtained was performed using Attenuated total reflection-Fourier Transform Infrared (ATR-FTIR) Spectroscopy, UV-visible spectroscopy, Transmission Electron Microscopy (TEM), Dynamic Light Scattering (DLS) [19].

The Attenuated total reflection-Fourier Transform Infrared (ATRFTIR) spectrum explains the interaction of gold nanoparticles with aqueous leaf biomolecules of Muntingia calabura. A robust and broad peak recorded at the wavenumbers $3259.49 \mathrm{~cm}^{-1}$ shows the presence of $\mathrm{O}-\mathrm{H}$ functional group with $\mathrm{H}$ bonded at $3259.49 \mathrm{~cm}^{-1}$ indicating the presence of phenol and $\mathrm{NH}$ functional groups in Muntingia calabura. An absorption band appeared at $1635.29 \mathrm{~cm}^{-1}$ correspondings to $\mathrm{C}=\mathrm{C}$ stretching vibrations confirming the presence of alkenes and aromatics (fig. 2). It was stated that the presence of phenols and alcohols is indicated by the $\mathrm{O}-\mathrm{H}$ stretching vibrations between $3200 \mathrm{~cm}^{-1}$ and $3400 \mathrm{~cm}-1$ and the presence of alkenes and aromatics is shown by the $\mathrm{C}=\mathrm{C}$ stretching vibrations between $1575 \mathrm{~cm}^{-1}$ and $1675 \mathrm{~cm}^{-1}$. The depth and width of the band are indicative of the intensity and abundance of the particular functional group in that band [20]. 


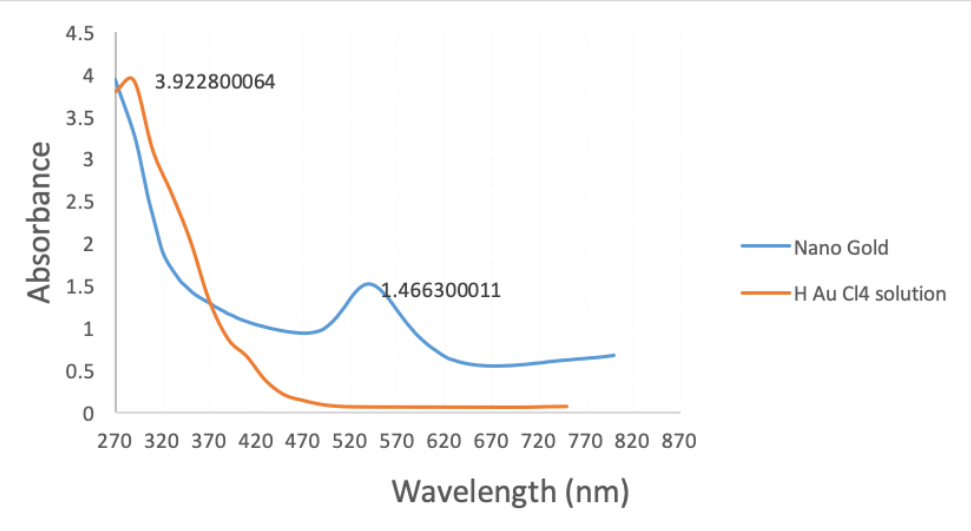

Fig. 1: UV spectra of $\mathrm{H} \mathrm{Au} \mathrm{Cl}_{4}$ aqueous solution (a) biosynthesis gold nanoparticles (b)

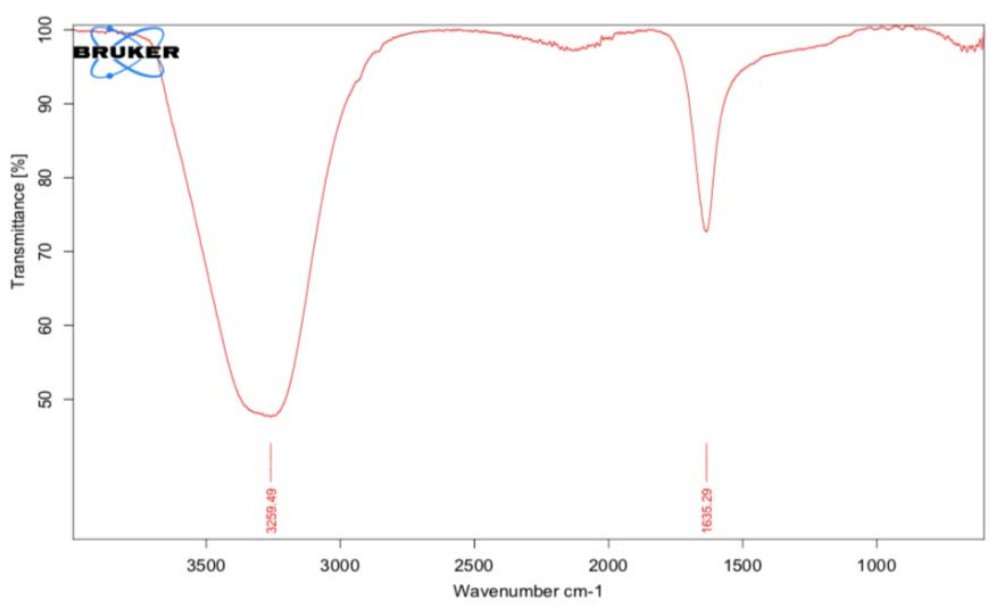

Fig. 2: FT-IR image of nano gold-Muntingia calabura

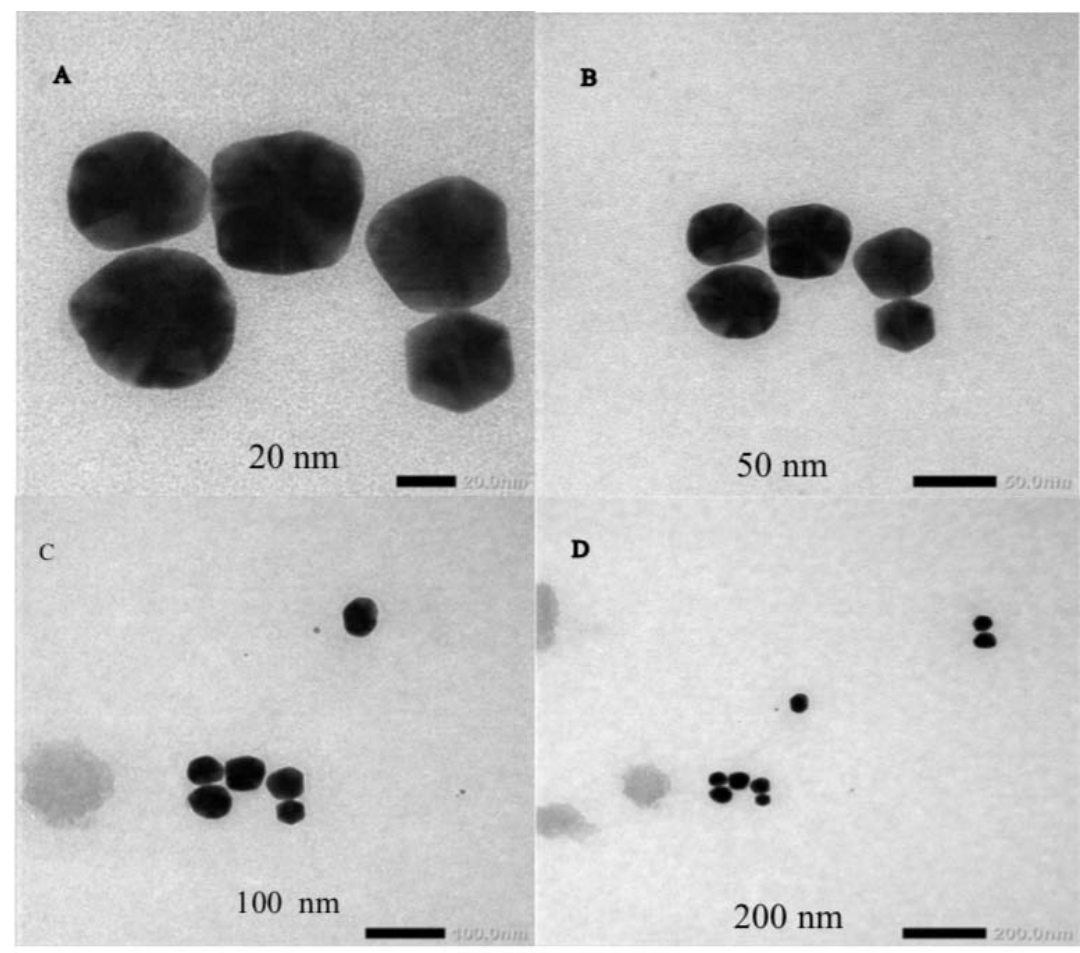

Fig. 3: Representative TEM images of the synthesized GNPs (A) on $20 \mathrm{~nm}$ scale (B) on $50 \mathrm{~nm}$ scale (C) on $100 \mathrm{~nm}$ scale (D) on $200 \mathrm{~nm}$ scale 


\section{TEM analysis of the synthesized gold nanoparticles (GNPs)}

After the completion of a synthesis process, the synthesized GNPs have been sampled for TEM analysis. In this process, the samples were prepared by placing a drop of obtained suspension on the copper grids. The grids were further dried and used for TEM analysis. A typical Transmission Electron Microscope (TEM) image of the nanoparticles formed is presented in fig. 3 . In general, the particles are spherical and mostly separated between gold nanoparticles. That indicated that the use of gummy Arabic in nanoparticle preparation could prevent aggregation of gold nanoparticles. These results illustrated the synthesis of $\mathrm{Au}{ }^{\left({ }^{\circ}\right)}$ nanoparticles through reduction of $\mathrm{Au}^{(3+)}$

\section{Determination of particle size and zeta potential}

The value of particle size distribution of gold nanoparticles was determined using a Particle Size Analyser (PSA) with Dynamic Light
Scattering (DLS) method. Particle size characterization is of particular significance to nanomedicine. The size equality of nanoparticles to biological moieties is considered to impart many of their unique medical character [21]. DLS is the most used instrument for the size characterization of spherical particles, a commercial tool being available and widespread [22].

In DLS, the nanoparticle solution is illuminated by a monochromatic. All the same, the primary objective of a DLS measurement is still for size (distribution). The size distribution histogram of dynamic light scattering (DLS) showed that the z-average size of the synthesized GNPs is $88,9 \mathrm{~nm}$ with a polydispersity index is 0.109 (fig. 4). It indicated that the distribution consisted of a single size mode without aggregates. The range for the PDI is from 0 to 1 . Values of PDI nearby to zero indicate a homogeneous dispersion, and those higher than 0.5 indicate high heterogeneity [23].

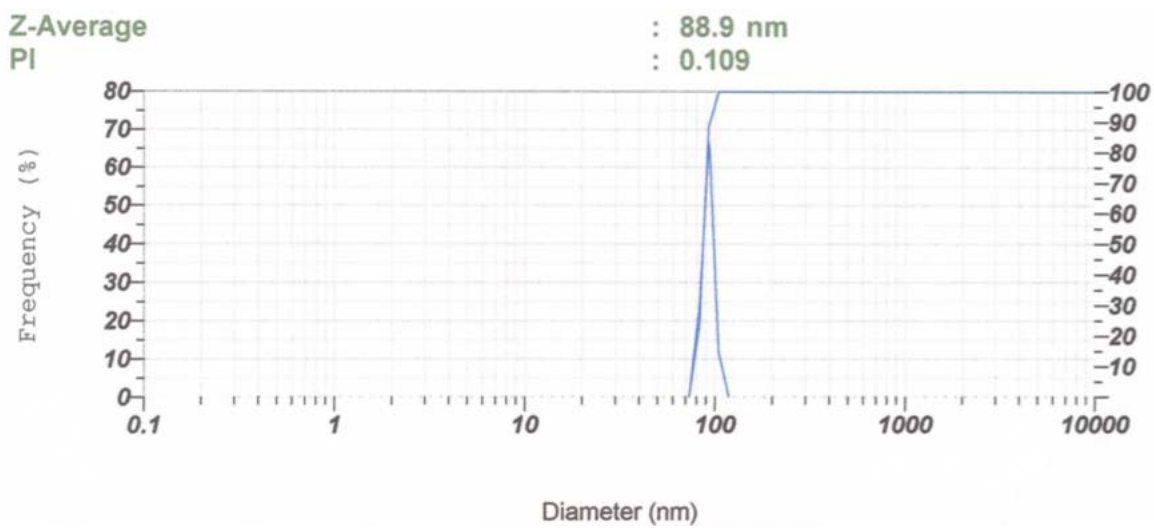

Fig. 4: The size distribution histogram of dynamic light scattering (DLS)

Also, zeta potential is an essential characteristic of nanoparticles, which is to predict the stability of the colloidal solution. The interaction among particles is critical to the stability of the colloidal solution. Zeta potential is a value that indicates repulsion force between particles. The colloidal solution stabilized by the presence of electrostatic repulsion rejected. The higher the repulsive force among particles rejected will cause the particles to be close to each other and will form aggregates. Nanoparticles with a zeta potential of $+/-30 \mathrm{mV}$ below stable nanoparticles [24].

The zeta potential and size of the nanoparticles can be controlled by various process parameters, including the amounts of emulsifier, drug, and polymer, the intensity and duration of homogenization, and the particle hardening profile. A reduction in the electrical charge is known to increase the flocculation and coalescence rates. Tolerable high zeta potential $(>-30 \mathrm{mV})$ ensures a stable emulsion by causing repulsion of adjacent droplets [25]. From the results of samples Zeta Potentials of the synthesized GNPs was-9.5 mV and below $30 \mathrm{mV}$ (fig. 5), maybe it caused for Arabic gum as a stabilizer. Arabic gum constituents are principally magnesium, calcium and potassium salts of the polysaccharide of Arabic acid, which on acid hydrolysis yields L-arabinose, Lrhamnose, D-galactose, D-glucuronic acid, and D-galactose. The solution of Arabic gum in water dissociates the salts and reveals the negative charge of Arabic gum, which allows the interaction with the positive charge of gold [23].

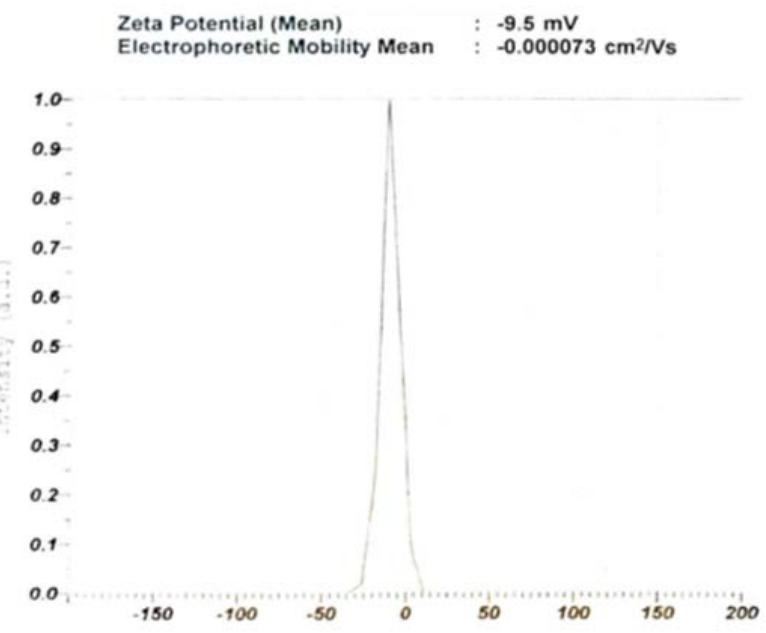

Fig. 5: Zeta potential of the synthesized GNPs 
The results of samples Zeta Potentials of the synthesized GNPs was$9.5 \mathrm{mV}$ also means that the solution of nanoparticles is considered an approximately neutral solution with a negative charge. Nanoparticles with a zeta potential between10 and $+10 \mathrm{mV}$ are considered an nearly neutral, while nanoparticles with zeta potentials of greater than $+30 \mathrm{mV}$ or less thä $\mathrm{mV}$ are considered strongly cationic and strongly anionic, respectively [21]

\section{The radical scavenging activity}

DPPH is a method which has been generally used as a measure for evaluating free radical-scavenging activities for antioxidant analysis. The DPPH test method is based on the reduction of DPPH, a free radical that is stable by antioxidants. The free radical DPPH with an odd electron gives a maximum absorption at $517 \mathrm{~nm}$ (purple colour). When Antioxidants react by DPPH, which is a stable free becomes paired off in the presence of a hydrogen donor (e. g., a free radical scavenging antioxidant) and is decreased to the DPPH and as a result, the absorbance's reduced from the DPPH [26]. To examine the antioxidant capacity through free radical scavenging by the test samples, the change in optical density of DPPH radicals is observed [27]. DPPH scavenging activity for the synthesis of GNPs was 24.1043 ppm (table 1), while that of the quercetin as a control, was $2.5554 \mathrm{ppm}$ (table 2). From table 1 indicated that synthesis of GNPs is a potent scavenger of superoxide radicals and the potential of antioxidants activities.

Table 1: Absorbance, \% inhibition and IC 50 of synthesis of GNPs (The values are means \pm SD of three replicates)

\begin{tabular}{lll}
\hline Concentration (ppm) & Absorbance \pm SD (nm) & \% Inhibition \pm SD (nm) \\
\hline 0 & $0.967 \pm 0.014$ & $0.000 \pm 0.000$ \\
10 & $0.688 \pm 0.029$ & $28.861 \pm 1.933$ \\
20 & $0.573 \pm 0.002$ & $40.743 \pm 1.296$ \\
30 & $0.366 \pm 0.032$ & $62.191 \pm 2.743$ \\
40 & $0.204 \pm 0.019$ & $78.962 \pm 1.654$ \\
\hline
\end{tabular}

Table 2: Absorbance, \% inhibition and IC 50 of quercetin (The values are means \pm SD of three replicates)

\begin{tabular}{lll}
\hline Concentration (ppm) & Absorbance \pm SD (nm) & \% Inhibition \pm SD (nm) \\
\hline 0 & $0.937 \pm 0.018$ & $0.000 \pm 0.000$ \\
1 & $0.752 \pm 0.006$ & $18.559 \pm 2.058$ \\
2 & $0.555 \pm 0.007$ & $39.893 \pm 1.691$ \\
3 & $0,363 \pm 0.008$ & $60.606 \pm 1.654$ \\
4 & $0,215 \pm 0.006$ & $76.67 \pm 2.036$ \\
\hline
\end{tabular}

\section{CONCLUSION}

Green synthesized GNPs showed enhanced biological activities and the advantages of using a green method for the production of nanoparticles having the potential of antioxidants activities.

\section{ACKNOWLEDGMENT}

The authors thanked to the Excellence Scholarships Indonesian Lecturers (BUDI-DN) from Indonesia Endowment Fund For Education (LPDP) for financial support to conduct these studies.

\section{AUTHORS CONTRIBUTIONS}

All the authors have contributed equally

\section{CONFLICT OF INTERESTS}

Declared none

\section{REFERENCES}

1. P Balashanmugam, K Pudupalayam Thangavelu. Biosynthesis characterization of silver nanoparticles using cassia roxburghii DC. aqueous extract, and coated on cotton cloth for effective antibacterial activity. Int J Nanomed 2015. p. 87.

2. MS Madhumithra, B Mosachristas, Tamil Selvi, Subashini. In vitro cytotoxicity of biosynthesized gold nanoparticles from shells of pistacia vera L. Int J Appl Pharm 2018;10:162.

3. S Ikram. Synthesis of gold nanoparticles using plant extract: an overview. Arch Med 2015;1:5.

4. S Ahmed, M Ahmad, BL Swami, S Ikram. A review on plants extract mediated synthesis of silver nanoparticles for antimicrobial applications: a green expertise. J Adv Res 2016;7:17-28.

5. S Duadarah, K Pujari, RD Durai, VHB Narayanan. Nanotechnology-based cosmeceuticals: a review. Int J Appl Pharm 2015;8:8-12.

6. Y Zeiri, P Elia, R Zach, S Hazan, S Kolusheva, Z Porat. Green synthesis of gold nanoparticles using plant extracts as reducing agents. Int J Nanomed 2014. p. 4007.

7. P Raveendran, J Fu, SL Wallen. Completely 'green' synthesis and stabilization of metal nanoparticles. J Am Chem Soc 2003;125:13940-1.
8. J Kasthuri, S Veerapandian, N Rajendiran. Biological synthesis of silver and gold nanoparticles using apiin as a reducing agent. Colloids Surf B Biointerfaces 2009;68:55-60.

9. D Philip. Green synthesis of gold and silver nanoparticles using Hibiscus rosa sinensis. Phys E Low Dimens Syst Nanostructures 2010;42:1417-24.

10. M Sechi. Single-step green synthesis and characterization of goldconjugated polyphenol nanoparticles withandnbsp; antioxidantandnbsp; and biological activities. Int J Nanomed 2014;23:4935-51.

11. K Marimuthu, R Dhanalakshmi. Qualitative and quantitative study of phytochemicals in Muntingia calabura L. leaf and fruit. World J Pharm Res 2014;3:1687-96.

12. D Ramada. Antioxidant activity: root, leaves, and fruits aqueous extracts of Muntingia calabura; 2015.

13. BH Nugroho, S Suparmi, MR Syifaudin. Preparation and characterization of gold nanoparticles lamtoro extract (Leucaena leucocephala (Lam.) de Wit) with eco-friendly biosynthesis process," presented at the 2nd international conference on chemistry, chemical process and engineering (IC3PE), Yogyakarta, Indonesia; 2018. p. 020076.

14. JS Djajadisastra, P Purnamasari, A Pujiyanto. Antioxidant activity of gold nanoparticles using gum arabic as a stabilizing agent. Int J Pharm Pharm Sci 2014;6:462-5.

15. DOB Apriandanu, Y Yulizar. The role of aqueous leaf extract of Tinospora crispa as reducing and capping agents for the synthesis of gold nanoparticles. IOP Conf Ser Mater Sci Eng 2017;188:012013.

16. K Preethi, N Vijayalakshmi, R Shamna, JM Sasikumar. In vitro antioxidant activity of extracts from fruits of Muntingia calabura Linn. from India. Pharmacogn J 2010;2:11-8.

17. S Ahmed, Annu S Ikram, S Yudha S. Biosynthesis of gold nanoparticles: a green approach. J Photochem Photobiol B 2016;161:141-53.

18. P Kuppusamy, MM Yusoff, GP Maniam, N Govindan. Biosynthesis of metallic nanoparticles using plant derivatives and their new avenues in pharmacological applications-an updated report. Saudi Pharm J 2016;24:473-84.

19. AK Mittal, Y Chisti, UC Banerjee. Synthesis of metallic nanoparticles using plant extracts. Biotechnol Adv 2013;31:346-56. 
20. I Demiral, NG Atilgan, S Şensoz. Production of biofuel from soft shell of pistachio (Pistacia Vera, L.). Chem Eng Commun 2008;196:104-15.

21. SE McNeil. Ed. Characterization of Nanoparticles Intended for Drug Delivery. Vol. 697. Totowa, NJ: Humana Press; 2011.

22. P Arenas Guerrero. Determination of the size distribution of non-spherical nanoparticles by electric birefringence-based methods. Sci Rep 2018;8. Doi:10.1038/s41598-018-27840-0

23. MR Avadi. Preparation and characterization of insulin nanoparticles using chitosan and arabic gum with ionic gelation method. Nanomed Nanotechnol Biol Med 2010;6:58-63.
24. VJ Mohanraj, Y Chen. Nanoparticles-a review. Trop J Pharm Res 2006;5:561-73.

25. GS Banker, J Siepmann, C Rhodes. Modern pharmaceutics. CRC Press; 2002.

26. TC Shekhar, G Anju. Antioxidant activity by DPPH radical scavenging method of ageratum conyzoides linn. leaves. Am J Ethnomed 2014;1:244-9.

27. Md N Alam, N J Bristi, Md Rafiquzzaman. Review on in vivo and in vitro methods evaluation of antioxidant activity. Saudi Pharm J 2013;21:143-52. 